Collective Action Problems AND REGIONAL INTEGRATION IN ASEAN

Hidetaka Yoshimatsu

CSGR Working Paper No 198/06

March 2006 


\title{
Collective Action Problems and Regional Integration in ASEAN
}

Hidetaka Yoshimatsu

CSGR Working Paper No 198/06

March 2006

\begin{abstract}
:
This article examines the states' attempt to overcome collective action problems for promoting regional integration, by highlighting such attempts by the members of the Association of Southeast Asian Nations (ASEAN). It considers two kinds of collective action problems: collaboration games where actors are lured to defect from an agreement in order to obtain short-term gains, and coordination games where actors face difficulty in reaching an agreement on which of multiple points will be chosen. This article argues that although ASEAN countries have not intended to establish a supranational body to resolve collective action problems, they have gradually developed feasible enforcement mechanisms by intensifying the centralised nature of the regional organisation. It also contends that some member states began to play a 'focal point' role in resolving coordination problems resulting from accelerated regional integration and market liberalisation, and the resolution of coordination problems has been pursued in a framework where extra-regional countries and environments play a significant role.
\end{abstract}

Keywords: collaboration game, coordination game, ASEAN Free Trade Area (AFTA), ASEAN Economic Community (AEC), harmonisation of standards, ASEAN divide

\section{Contact Details:}

Hidetaka Yoshimatsu, Ph.D.

The College of Asia Pacific Studies, Ritsumeikan Asia Pacific University, Japan

1-1 Jumonjibaru, Beppu

Oita, 874-8577 Japan

Tel: 81-977-78-1242

Fax: 81-977-26-0863

Email: yoshih@apu.ac.jp 


\section{Introduction}

Regionalism and regional integration have been one of the most dynamic phenomena in the current international setting. Since the early 1990s, an initiative to develop and strengthen regional institutions has intensified on a global scale. This move led to the creation of the European Union (EU) in Europe, North American Free Trade Agreement (NAFTA) in North America, and Mercosur in Latin America.

Regionalism has been of great importance in terms of international relations (IR) theory. Regional integration is an attempt to realise mutual gains from cooperation within a group of self-motivated states in an anarchic international system. In order to attain a successful regional cohesion, the states have to overcome collective action problems that are endemic to international cooperation. IR theory has provided the explanation of how and under what conditions the states have promoted cooperation to achieve collective interests of the entire region.

The successful experiences of regional integration in Europe have been regarded as a model for similar attempts in other parts of the world. The European nations have established solid and institutionalised mechanisms for inter-state cooperation largely under the leadership role of major states and the creation and advancement of supranational agents. If European integration is evaluated in terms of the states' interest coordination, it might be alleged that the core factor producing the European fortune lay in the states' successful resolution of dilemmas resulting from their strategic interaction. It is, therefore, valuable to examine how states can overcome the dilemma of collection actions pertinent to regional integration.

In considering collective action problems in international relations, two kinds of games matter. The first is collaboration games where actors are lured to defect from an agreement in order to obtain short-term gains. The problem in this game is to attain a better off situation by making the actors abandon a dominant strategy. The second is coordination games where actors face difficulty in reaching an agreement on which of multiple points will be chosen. The problem in this game is to coordinate the actors' behaviour and avoid undesirable outcomes by reaching an agreement on the certain set of patterns of code. The dilemma resulting from the two games impede the states from entering into cooperative action. 
This article examines the states' attempt to overcome collective action problems for promoting regional integration, by highlighting such attempts by the members of the Association of Southeast Asian Nations (ASEAN). The central arguments that this article advances are threefold. First, although ASEAN countries have not intended to establish a supranational body to resolve collective action problems, they have gradually developed feasible enforcement mechanisms by intensifying the centralised nature of the regional organisation. Second, some states within the region began to play a 'focal point' role in resolving coordination problems resulting from accelerated regional integration and market liberalisation. Third, the resolution of coordination problems has been pursued in a framework where extra-regional countries and environments play a significant role.

In the following section, I take a look at the literature on collective action problems concerning inter-state cooperation, and identify two kinds of dilemma. I then investigate collaboration problems pertinent to regional integration in Southeast Asia and examine ASEAN members' responses to the problems. The third section considers coordination problems with respect to regional integration in Southeast Asia.

\section{COLLECTIVE ACTION PROBLEMS AND REGIONAL INTEGRATION}

There are two kinds of collective action dilemma in promoting international cooperation: collaboration game and coordination game. The collaboration game indicates the situation where 'independent decision making leads to equilibrium outcomes that are Pareto-deficit - outcomes in which all actors prefer another given outcome to the equilibrium outcome' (Stein 1983. p. 120). A typical example of this game is the prisoners' dilemma where individual players' rational, dominant strategies lead them to an equilibrium outcome in which they are worse of than if they cooperated. In this game, the rational actors' pursuit of self-interest results in their being worse off than if they cooperate by abandoning their dominant strategy. Accordingly, the resolution of the collaboration game requires the actors to move away from the suboptimal equilibrium by abstaining from pursuit of narrow self-interest.

The collaboration game has been intensively discussed in the study of international relations. Inter-state agreements designed to achieve optimal common goals tend to be unstable and fragile. This is because self-interested states have 
substantial incentives to defect from the established patterns of behaviour in order to get better gains in the short run. However, states are allured to keep the agreements under the condition of a combination of indefinite or uncertain repetition and the threat of loss of future benefits from cooperation (Axelrod 1984). Given these conditions, states are not tempted to defect from cooperative arrangements for fear of retaliation and loss of reputation. However, these arguments tend to break down when other states find it difficult to determine whether a state has violated commonly agreed rules due to ambiguity and incomplete information. When a conflict occurs between states, the states other than direct parties have difficulty in finding truth in various claims and counterclaims made by the parties.

The coordination game is another game that impedes the development of cooperation. The coordination game indicates the situation 'with multiple equilibria (two equilibria if there are only two actors each with two choices) in which coordination is required if the actors are to avoid that least preferred outcome' (Stein 1983, p. 125). A typical example of this game is called the Battle of the Sexes where both members of a couple prefer to do something together, but they disagree on their preferred outcome, vacationing in the mountains or at the ocean. The choice of mountains or ocean matters because it gives one player a higher payoff than the alternative (Krasner 1991, pp. 33940). The actors have strong incentives to achieve something jointly but some differences over where to coordinate for this objective. The key problem in this situation is not to avoid temptation to defect, but to decide on which of the two equilibrium points will be chosen.

Importantly, repeated coordination games make cooperation among actors more difficult because they provoke distributional problems. The outcome of iterated games provides an actor whose decisions are chosen with sufficient satisfaction, while putting other actors with second-best solutions in a growing discontent. Questions of fairness and equitable distribution of gains from cooperation need to be addressed to prevent an actor with discontent from derailing the cooperation process (Mattli 1999, p. 56).

In international relations, coordination games occur when the states have to agree on certain codes of conduct for attaining common goals, but have different preferences on which codes are adopted. Under such conditions, the states need to coordinate their 
preferences and policies for common rules of the game, and adopt measures to resolve distributional conflict.

There are two methods to overcome dilemmas from the two games in international relations. The first is the establishment of international institutions. The necessary form of institutions differs between collaboration games and coordination games. As for the collaboration games, a centralised, formal organisation is required. The centralised organisation needs to provide extensive information on the players' behaviour. This is because undetected defection will be costly for those who continue to cooperate and will complicate attempt at retaliation. Moreover, the centralised organisation is expected to prevent a state from defecting from agreements by regulating their actions within agreed-upon rules. The centralised mechanism of adjudication provides procedures to support formal agreements (Snidal 1985, p. 938). In sum, institutional mechanisms for extensive monitoring and assessment of compliance are necessary for overcoming collaboration problems.

In the case of coordination games, a centralised, formal organisation with strong mechanisms for monitoring and enforcement is not necessarily required. Since no state would gain by departing from an established agreement, each member of a group needs to devote little attention to the prevention of cheating (Martin 1992, p. 776). The main concern in coordination games is the harmonisation of rules and policies, and this requires low levels of institutionalisation. Accordingly, institutions are expected to perform information gathering and information consultation about the preferences and policies of the states and to provide a forum for the resolution of bargaining problems concerning the choice of specific rules (Snidal 1985, p. 938).

However, when distributional problems resulting from repeated coordination games are serious, institutions need to perform additional functions. Institutions moderate distributional conflict by identifying one possible equilibrium point as the default or obvious one, thus reducing inter-state bargaining about the choice of a particular code of conduct, and by keeping account of deals struck, compromises made, and gains achieved in complex multi-issue institutions (Martin and Simmons 1998, p. 745).

The second method to overcome dilemmas from collective action is leadership. The existence of a hegemonic state with preponderant material resources can facilitate 
the resolution of collaboration games. The single dominant state has willingness and capability to provide certain kind of international public goods including a market for distress goods, a steady flow of capital, a stable structure of exchange rates, and so forth (Kindleberger 1981: Gilpin 1987. pp. 73-80). The hegemonic state also blocks some members' free-riding, an action to benefit from a public good without paying their share towards providing that good. Thus, leadership by a hegemonic state can overcome the collaboration game by articulating and enforcing the rules of interaction among the states.

In coordination games, leadership is also important. If there is a single, powerful state within a group, the solution of coordination games might be easy. When all or a majority of the states within the group regard a dominant state as more important to the group than that of any other state, they will find it in their interest to go along with the state's preferences and policies. Such a solution removes the need for extensive discussions and is likely to be the least costly change within the group (Martin 1992, p. 777). Thus, a dominant state within the group may serve as a focal point in the coordination of rules, regulations and policies. ${ }^{1}$ Moreover, the existence of a single, powerful state might resolve dilemmas from the distributional consequences of coordination. The leading state may be able and willing to assume the role of a paymaster, easing distributional tensions that arise from the inequitable distribution of gains from cooperation, for example, through side-payments (Mattli 1999, p. 56).

The above argument regarding collective action problems is applied to regional integration. The success and failure of regional integration is explained by the region's capabilities to overcome collaboration games and coordination games. A region that has attained a high level of regional cohesion has resolved dilemmas from the member states' strategic interaction by developing a formal regional organisation with monitoring and enforcement authorities, and by holding a state that has will and capabilities to become a focal point for regional affairs and assume disproportionately large burdens for rectifying distributional inequalities.

\footnotetext{
1 The concept of focal point was originally introduced by Schelling. It is referred to as the 'point for each person's expectation of what the other expects him to expect to be expected to do' (Schelling 1960, p.57).
} 
A representative region that has successfully developed regional integration with both an effective formal organisation and an undisputed leader state is Europe. EU members gradually changed their previous pattern of bilateral, self-enforcing arrangements into a pattern of third-party enforcement mechanisms under the centralised supranational agents. Agents such as the European Commission and the European Count of Justice (ECJ) have qualified to set up and guarantee the legal systems to enforce decision on the member states, and the expanding scope of regional affairs has been covered by the systems. The commission has observed whether individuals, companies and member states do not act in ways which run counter to the treaties or EU secondary law (Mattli 1999, p. 100). The ECJ has played monitoring and enforcing roles by securing that EU law has primacy over national legislation and has direct effects on the members' society. Especially after the return to the qualified majority voting in the Single European Act in 1987, both the centralisation of decisionmaking systems and the surrender of individual states' decision-making power were strengthened.

In the European integration process, Germany acted as the key policy initiator and agenda setter. The country took the lead in launching the idea of the European Monetary System (EMS) in 1978, relaunching the Economic and Monetary Union (EMU) in 1988, and a calling for an inter-governmental conference on political union to parallel the proposed EMU in 1990 (Katzenstein 1997, p. 26). Germany launched nearly all its initiatives with France or other members in order to avoid the temptation of trying to set the European agenda unilaterally. Moreover, Germany has been by far the largest net contributor to the EU budget. By 1996, Germany's financial contribution to the EU amounted to some two-thirds of the net revenue of the union, double its share of the total gross domestic product in the EU (Katzenstein 1997, p. 28).

While the European success has provided a direct spur to regional integration in other parts of the world, the European model is not applied to other regions in a straightforward way. Most regions hold states that are reluctant to allow a regional organisation to make surveillance and enforcement decisions on their behaviour, and lack a dominant state that takes a leadership role in advancing collective interests of the entire region. However, these regions have substantial incentives to bind the economies of the regional states together and to develop collective mechanisms to cope with 
problems arising inside or outside the regions. How have such regions sought to achieve these objectives by overcoming the two types of collective action dilemmas? What kinds of regional institutions or organisations have they developed in order to resolve dilemmas deriving from the states' strategic interaction? How has a major state in the regions behaved in order to advance collective benefits for regional cohesion? This article addresses these questions by taking up as a case ASEAN's commitments to regional integration since the late 1990s.

Since the late 1990s, ASEAN members have faced serious economic and political challenges due to the Asian financial crisis in 1997-98 and likely marginalisation due to the rapid economic growth of China and India. In order to respond positively to these climates, the member states had to pursue deeper regional integration. A main interest in this respect is how the ASEAN states have sought to resolve collaboration problems by preventing the defection of a member from agreements to promote regional integration. The deepening of regional integration required the harmonisation of policies and standards adopted by member states. Moreover, the expansion of membership to the Indochina countries in the late 1990s provided ASEAN with the development gap problem between the old and new members. The process of economic integration under the old members' initiatives might exacerbate the development gap problem. A main interest in this respect is how the ASEAN states have sought to cope with these coordination problems by setting up a focal point for common goals.

\section{ECONOMIC INTEGRATION AND COLLABORATION DILEMMA}

\section{The slow progress of market integration in the 1990s}

A milestone in ASEAN's attempt to promote economic integration was the ASEAN Free Trade Area (AFTA). At the fourth summit in January 1992, the ASEAN leaders agreed to establish a free trade area by the year 2008 by signing the Framework Agreement on Enhancing ASEAN Economic Cooperation. Under the Common Effective Preferential Tariff (CEPT) Scheme, the main mechanism for achieving AFTA, existing tariffs on manufactured goods and processed agricultural products would lower to between o to $5 \%$ and quantitative restrictions and other non-tariff barriers would be eliminated. 
ASEAN members expanded the scope of market liberalisation. At the fifth summit in 1995, ASEAN leaders agreed on the ASEAN Framework Agreement on Services. This agreement aimed at promoting market liberalisation in the areas of finances, marine transport, telecommunications, aviation, tourism, construction, and business. In 1998, the Framework Agreement on the ASEAN Investment Area was also reached. Moreover, ASEAN provided a mechanism for dispute settlement. ${ }^{2}$ In November 1996, the ASEAN Economic Ministers (AEMs) signed the Protocol on a Dispute Settlement Mechanism (DSM). The mechanism was quite inter-governmental. When no amicable settlement could be reached through bilateral consultation and negotiations, a dispute can be referred to a senior economic officials meeting (SEOM) first, and then appealed to an AEM meeting. Moreover, the mechanism did not provide sufficient regulations to implement the final ruling. A member state that fails to comply with the ruling faces no punitive measures, but shall enter into negotiations with any party having involved the dispute settlement procedures with a view to developing mutually acceptable compensation (Hund 2002, p. 108).

Despite the launching of various programmes for market liberalisation, the actual implementation progress did not go smoothly. The agreement to create AFTA was reached within ten months of its initial proposal. Accordingly, the agreement did not include details for implementation, and backsliding moves immediately emerged. At the third AFTA Council in December 1992, each member state revealed the CEPT plan. But, there were variations in the time to begin trade liberalisation: Singapore from January 1993; Malaysia from 1993; Brunei from 1994; Thailand and Indonesia from 1995; and the Philippines from 1996 (Yamakage 1997, p. 199). The diversity in implementation became apparent only one year after the conclusion of the agreement.

More importantly, the implementation of AFTA was undermined by some states' attempt to defect from the agreement. Among several incidents, two were typical. The first was Malaysia's defection from implementing tariff reduction of auto-related products. At an AEM meeting in May 2000, Malaysia requested a delay until 2005 in transferring 218 tariff lines of complete knocked-down (CKD) and complete built-up

\footnotetext{
2 The 1992 CEPT Agreement did not include a mechanism for dispute settlement. It only stipulated in Article 8 that member states should try to amicably settle any disputes arising from implementation of AFTA through consultation.
} 
(CBU) automotive products from its Temporary Exclusion List to the Inclusion List. Originally, Malaysia was to start the transfer in 2000 and in effect bring down the import tariffs of automobile-related products to $20 \%$ or less, and gradually to $0-5 \%$ by the year 2003. Thailand, the major auto producer country in Southeast Asia, opposed Malaysia's policy, threatening to delay import tariff reduction on palm oils, the main Malaysian export item. This issue was settled at the thirty-second AEM meeting in November 2000 with the adoption of the Protocol Regarding the Interpretation of the CEPT Scheme Temporary Exclusion List. ${ }^{3}$

Second, Singapore and the Philippines had conflicts over import tariff reduction on the latter's petrochemical products. In December 2002, Manila submitted a list of 11 petrochemical products whose tariffs would be maintained at between 7 to $10 \%$. According to the CEPT scheme, the Philippines was to have lowered tariffs on the products to $5 \%$. Singapore accused Manila's decision as hurting AFTA's reputation as a cohesive trading bloc and asked for compensation for damages suffered by its exporters. Manuel Roxas, Secretary of Trade and Industry, stated that the Philippines remained committed to ASEAN solidarity but, 'we are considering of our commitment to ASEAN's obligation. But, we have national interest to consider. The Philippines deems the petrochemical industries to be a strategic sector' ${ }^{4}$

The above incidents indicated ASEAN's failure to secure the original commitments to market integration. AFTA's non-binding, flexible character allowed a member to defect from an agreement when she was forced to protect the interests of major domestic industries. The other members were unable to block such moves, being forced to adopt the downward, patchwork revisions of commitments from those previously agreed. Indeed, informality, one of the norms of the 'ASEAN Way', should be compensated by 'peer pressure'. ${ }^{5}$ However, peer pressure did not work effectively in

\footnotetext{
3 The protocol may be invoked by member countries, which face problems in meeting their CEPT obligations and allow the countries to temporarily delay the transfer of a product from the TEL into the IL or to temporarily suspend its concession on a product already transferred into the IL. The protocol also provides for compensation and retaliation that were envisaged to inject tight disciplines. This protocol was considered with Article 28 of GATT 1994, and provided a transparent process for countries to modify their concession with compensation under the system of checks and balances.

4 Agence France Presse, June 16, 2003.

5 The ASEAN way is a set of norms that include the non-interference principle, informal consultation, pragmatic expediency, consensus-building, and flexible incrementalism (Acharya 1997, pp. 329-33; Liu 2003, pp. 20-22).
} 
AFTA's implementation process. ASEAN, an intergovernmental 'neighbourhood watch group', was not equipped with the authorities to enforce the agreement with legallybased monitoring mechanisms (Khoo 2000). ASEAN's weak institutional character could not resolve collaboration games in which each member pursued short-term gains rather than long-term collective benefits.

\section{The strength of implementation mechanisms}

In the new millennium, a concrete initiative for further regional integration was set forth. At the ninth summit in October 2003, ASEAN leaders agreed to establish an ASEAN Economic Community (AEC). ${ }^{6}$ The AEC intended to transform ASEAN into a common market by 2020 along the lines of the European Economic Community. The AEC would be a single market and production base with a free flow of goods, services, investment, and skilled labour. Unlike a normal common market, the AEC restricted a flow of labour to skilled labourers and business persons, and did not plan to set up a uniform tariff rate on non-members. Accordingly, the AEC is called a FTA-plus agreement.

ASEAN members strengthened the AEC concept further the following year. At the tenth summit in November 2004, ASEAN leaders launched the Vientiane Action Programme (VAP). The VAP was the second mid-term (2005-2010) plan, succeeding the Hanoi Plan of Action that ended in 2004. ${ }^{7}$ The programme contained clearer goals and strategies for realising the AEC: integration completion in the eleven priority sectors before 2010; tariff elimination for products by 2010 for old ASEAN members and 2015 for new ASEAN members. The VAP prepared for a monitoring and evaluation system. The system is based on a scorecard that comprises both a consolidated assessment mechanism at the macro level and a quantitative rating mechanism at the project level.

\footnotetext{
6 The AEC is one of three pillars that make up the ASEAN Community as declared by the ASEAN leaders in the Bali Concord II. The concord was an accord agreed at the ninth summit in October 2003. The other two pillars are the ASEAN Security Community and the ASEAN Socio-Cultural Community. The Bali Concord II was the new ASEAN vision, 27 years after the first Bali Concord was signed by the then ASEAN-5.

7 The Hanoi Plan of Action, launched in December 1998, was the first of action plans designed to realise goals of the ASEAN Vision 2020.
} 
In accordance with the launching of the AEC, ASEAN members strengthened mechanisms to ensure the proper implementation of all economic agreements and the expeditious resolution of any disputes. At the thirty-sixth AEM meeting in September 2004, the ministers agreed to set up three new mechanisms. The first was a legal unit within the ASEAN Secretariat. This unit aimed to provide governments with legal advice on trade disputes. The second was the ASEAN Consultation to Solve Trade and Investment Issues (ACT). The ACT was a network of government focal points where private sector complaints and operational problems in implementation could be channelled for speedy resolution. The third was the ASEAN Compliance Body (ACB). The body would perform a quasi-judicial function by reviewing a trade dispute and issuing a judgement that is not legally binding, but can be used to take steps to settle the disputes. Importantly, these mechanisms were modelled from the EU and World Trade Organisation (WTO). Whereas the ACT imitated the example of the EU Solvit mechanism, the ACB was modelled after the WTO Textile Monitoring Body.

The ASEAN members strengthened a formal dispute settlement mechanism. In the Bali Concord II, ASEAN leaders stated that ASEAN shall 'strengthen the institutional mechanisms of ASEAN, including the improvement of the existing ASEAN Dispute Settlement Mechanism to ensure expeditious and legally binding resolution of any economic disputes'. ${ }^{8}$ In November 2004, the 1996 Protocol on DSM was replaced with the ASEAN Protocol on Enhanced Dispute Settlement Mechanism. The new protocol strengthened the DSM system in various ways. First, the new protocol reduced ambiguity. While the old protocol had only twelve articles with short passages, the new protocol had twenty-one articles with substantial passages. Second, the new protocol stipulated the establishment of the Appellate Body. The body, comprised of independent and experienced professionals, makes judgements on a legal basis. Third, the new protocol provided procedures for the surveillance of implementation. While the new protocol still admitted strong involvement of SEOM, an inter-governmental body, it established a tighter dispute settlement system following the WTO’s Dispute Settlement Understanding.

\footnotetext{
8 Declaration of ASEAN Concord II (Bali Concord II), available online at http://www.aseansec.org/15159.htm 
In the new programmes and mechanisms, the role and function of the ASEAN Secretariat were strengthened. The VAP spelled out measures to strengthen the function of the ASEAN Secretariat. First, the VAP raised thematic projects that have to be implemented jointly by two or more ASEAN bodies. 'The ASEAN Secretariat will facilitate the consultation process among ASEAN bodies and seek the most efficient modality in setting up the appropriate institutional arrangement at the programme/project level'. ${ }^{9}$ Second, progress in the VAP implementation shall be reported annually by the Secretary-General to the ASEAN Summit, and formal reviews shall be undertaken by the ASEAN Secretariat every two years. ${ }^{10}$ As for the DSM, Article 19 (Responsibilities of the Secretariat) of the new DSM stipulates that the Secretariat 'shall have the responsibility of assisting the panels and the Appellate Body especially on the legal, historical and the procedural aspects of the matters'.

In addition to the direct strength of the ASEAN Secretariat, new institutions that would enhance the authorities and roles of the Secretariat were introduced. First, the ASEAN members agreed to set up an ASEAN Development Fund in the VAP. The fund would serve as ASEAN's common pool of financial resources to be made up from contribution of the member countries, based on a mutually acceptable scheme. ${ }^{11}$ The fund was expected to be used for complex projects of relatively large scale for seed funding and for full support for small scale projects of a confidential or strategic nature. This is a part of resource 'pooling', in which member governments allow the use of their funds for shared objectives. Moreover, the VAP aims to embark on fund-raising programmes to encourage and generate private sector support for ASEAN activities. If the amount of common fund that is managed and allocated by the Secretariat increases, it would raise its capacity and authority.

The second is institutional involvement of the business actors in the ASEAN integration process. At the seventh summit in November 2001, an initiative to launch the ASEAN Business Advisory Council (ABAC) was approved, and the ABAC held the inaugural meeting in April 2003. The ABAC delivers requests and preferences of the private sector to the policy-making process by publishing a report directly reached to

\footnotetext{
9 Vientiane Action Programme, 5.2 Institutional Arrangements.

10 Vientiane Action Programme, 5.3 Monitoring and Evaluation.

11 Vientiane Action Programme, 5.1 Resource Mobilisation.
} 
ASEAN leaders. In the European integration process, the business associations played a critical role in promoting the unification of the European market, and their activities were often conducted in close collaboration with the European Commission. With no political constituency of their own, the commissioners looked to the business associations to strengthen their powers and authorities vis-à-vis the member states (Cowles 1995, p. 230). Unlike the European case where the business associations were formed by individual corporate executives, the ABAC was organised by ASEAN leaders. However, it has the potential of becoming a strong ally to the Secretariat whose major mission is to promote regional integration.

It is broadly known that ASEAN members were extremely reluctant to relinquish their power to a supranational body. In general, the members' vital interest has been the maintenance of domestic cohesion and the relinquishing of sovereignty to a supranational body has been regarded as jeopardising this vital interest. More narrowly, the ruling elites of each state who have developed domestic institutions in favour of the status quo were unwilling to cede power to an independent, unpredictable agency (Tan 2005, p. 9). This propensity was seen when the ASEAN members conceptualised the AEC. Before the launching of the AEC, the AEMs commissioned a consultant company, McKinsey and Company, in 2001 to conduct an ASEAN Competitiveness Study. The McKinsey's report suggested two plans for increased economic integration: a sector-based approach and a reform to create regional institutions strong enough to manage complete integration efforts (Schwarz and Villinger 2004). In preparation for the AEC concept, the ASEAN members also asked for opinions from the Institute of Southeast Asian Studies (ISEAS) and ASEAN Institute of Strategic and International Studies (ASEAN-ISIS), and both research institutes recommended the creation of appropriate supranational institutions to facilitate economic integration. However, the High-Level Task Force (HLTF) on ASEAN Economic Integration did not adopt the idea of creating supranational institutions (Hew and Soesastro 2003, p. 295). ${ }^{12}$

ASEAN members' reluctance to delegate the authority to a supranational institution did not imply their unwillingness to strengthen reliable mechanisms and processes to secure the compliance of agreements. Davidson (2005, p. 19) presents two

12 The AEMs set up the HLTF whose mission was to explore the AEC concept and other ideas on intensifying ASEAN economic cooperation and deepening market integration. 
aspects of delegation: delegating the authority to interpret/ apply the rules and resolve disputes; and delegating the authority to make further rules. ASEAN members are cautious about delegating the authority to make further rules, but they have gradually delegated the authority to interpret/apply the rules and resolve disputes. The members established clearer goals towards a unified market and adopted more rule-based mechanisms to ensure the proper implementation of agreements. These moves were accompanied by strengthening the roles and authorities of the ASEAN Secretariat as a formal, centralised body to overview ASEAN's efforts to advance regional cohesion.

In brief, when ASEAN members launched an initiative to form a common market, they strengthened mechanisms to overcome the problems of collaboration dilemma, which were common in the AFTA implementation process. They strengthened enforcement mechanisms and the monitoring systems of the agreements. The ASEAN members had no intentions of delegating authority to ASEAN and changing it into a supranational body. However, the formal and centralised nature of the organisation gradually developed through enhanced functions of the ASEAN Secretariat.

\section{ECONOMIC INTEGRATION AND COORDINATION PROBLEMS}

\section{The harmonisation of standards for the integrated market}

The realisation of a unified market in a given region requires the harmonisation of policies and standards adopted by the states in the region. This is particularly important for trade facilitation and industrial competitiveness. In Europe, for instance, the harmonisation of national standards and the adoption of mutual recognition constituted a key to the smooth process of market integration (Sandholtz and Zysman 1989, p. 116; Hufbauer 2000, p. 11-12).

ASEAN has endeavoured to harmonise national standards with international ones and implement mutual recognition agreements (MRAs) on conformity assessment through the ASEAN Consultative Committee on Standards and Quality (ACCSQ). The ACCSQ, under the SEOM, was established in 1992 so as to eliminate technical trade barriers pertinent to standards and conformance. Its members are the national standard bodies of member states and its activities have been conducted by various working groups. The harmonisation of standards has been implemented through the alignment of 
national standards with relevant international standards such as those set by the International Organisation for Standardisation (ISO), International Electro-technical Commission (IEC) and International Telecommunications Union (ITU).

ASEAN leaders agreed to harmonise product standards for 20 priority product groups at the sixth summit in December 1998. Then, an additional harmonisation was agreed on the electrical safety aspects of electrical products and on the subject of electromagnetic compatibility (EMC) in 1999. The harmonisation of standards for 20 priority product groups covering 59 international standards was completed by the end of 2003. The groups included consumer products such as radios, television sets, refrigerators, air conditioners and telephones. The 71 safety standards and ten EMC standards were harmonised in July 2004.

As for MRAs, ASEAN leaders signed the Framework Agreement on Mutual Recognition Arrangement at the sixth summit in 1998. The agreement set out the general principles, governing the development of sectoral or product-based MRAs. The AEMs signed in April 2002 the ASEAN Sectoral Mutual Recognition Arrangement for Electrical and Electronic Equipment. This agreement was important because electrical and electronic equipment accounted for a significant portion of intra-ASEAN trade. Then, the Agreement on ASEAN Harmonised Cosmetic Regulatory Scheme was signed by the AEMs in September 2003.

Importantly, ASEAN promoted the harmonisation of technical standards in collaboration with other states. For instance, Japan and the United States have been deeply involved in the development of the activities of ACCSQ. ASEAN and Japan has organised an ACCSQ-METI meeting since 1995. In September 2001, METI proposed formulating ASEAN Standards and Conformity Cooperation Programme at an AEMMETI meeting. The programme, announced in May 2003, analysed situations and needs of ASEAN members and provided concrete measures for international standards and conformity evaluation.

As for collaboration with the United States, ASEAN and the US Department of Commerce have implemented cooperation since 1996. In April 2001, both bodies signed the Memorandum of Cooperation on Trade-Related Standards and Conformance Issues. In addition, ASEAN and the US agreed to develop a three-year action plan. They identified preliminary sectors of mutual interest including electrical and 
electronics equipment, telecommunications and IT products, foods and construction materials. They also organised a workshop to familiarise relevant regulatory agencies and industries with the requirements.

Despite ACCSQ's positive commitments, the standardisations process has not gone smoothly. When ASEAN leaders agreed to harmonise product standards through alignment with international standards for 20 priority product groups in 1998, they fixed the deadline at the year 2000. However, this harmonisation was completed in 2003, three years after the deadline. Rodolfo Severino, former Secretary-General of ASEAN, lamented in his last report to the ASEAN leaders that 'the process of integration has generally stalled. To be sure, some progress has been made, notably in AFTA, but progress has fallen short of measuring up to the challenges faced by our region and carrying out the leaders’ vision and resolve” (Severino 2000, p. 477).

The problems in standards harmonisation and MRAs might be overcome when there is a state to become a focal point. In the case of standards harmonisation in the European integration, Germany played a focal point role. The German national standards-setting organisation, Deutsches Institut fur Normen (DIN), set the tone in a wide range of European industries, and actively involved in operations of European standards-setting organisations such as CEN and CENELEC, controlling the largest number of secretariats for technical committees within the organisations (Mattli 1999, p. 103). ${ }^{13}$ In Southeast Asia, there was no such state that took the lead in creating common front in standards harmonisation for the entire region.

Singapore and Thailand began to play a pivotal role in the field of standards harmonisation and MRAs. Both states established the Singapore-Thailand Enhanced Economic Relationship (STEER) framework by holding an inaugural meeting for this framework in August 2003. One of the major targets of the STEER was the development of MRAs in the area of mutual interests such as ICT and electronic and electrical products. In fact, David Lim, Acting Minister of Information Communications and the Arts of Singapore, stated at a Singapore-Thailand Chamber of Commerce meeting in March 2003 as follows:

13 CEN and CENELEC are French acronyms of the European Standards Committee and European Electrical Standards Committee, respectively. 
One initiative is the establishment of a Mutual Recognition Agreement (MRA) for telecom equipment. Such an agreement will enable Thai telecom equipment that have been tested and certified in Thailand to be accepted in Singapore without further certification, and vice versa. This will save our businessmen money and time, and will boost trade in such ICT products. Consumers will also benefit, as lower costs and higher volumes will help to drive down prices. ${ }^{14}$

The two states' intention of becoming a focal point for policy coordination in the entire region was explicitly stated by Singaporean Prime Minister Goh. At the inaugural meeting of the ASEAN Business and Investment Summit, Goh stated that 'Our aim is to showcase these bilateral projects and their results, to encourage other members of ASEAN to join in. Both countries will take first to the dance floor to "tango". When other ASEAN members join in later, we will have a livelier party' ${ }^{15}$

While Singapore and Thailand began to play a focal point role in promoting coordination in standards harmonisation and MRAs for regional integration, they also created region-divergent forces by promoting economic bilateralism. By the end of 2004, Singapore concluded an FTA with Japan, Australia, New Zealand, South Korea and the United States while Thailand concluded with Australia and New Zealand. Singapore and Thailand expected that this bilateral move would urge other ASEAN fellows to promote market integration. However, some of these fellows were apprehensive that these bilateral strategies would undermine ASEAN's solidarity (Dent 2005). Importantly, Singapore and Thailand pursued this bilateral strategy largely because they needed to secure individual interests in increasing competitive challenges in the globalisation era. On the one hand, they had to strengthen their economic position in the global market, and on the other hand, they sought to respond positively to direct challenges posed by China's growing economic potent. The growing integration of the economies of Thailand and Singapore into the global and extra-regional environments constrained their policy choices for regional economic affairs.

In summary, given the growing threat of marginalisation due to intensive moves towards regional cohesion in other parts of the world and the robust growth of the

\footnotetext{
14 'Growing the Asian ICT Market Together, Address by Mr David T E Lim, Acting Minister for Information, Communications and the Arts, available online at http://unpan1.un.org/intradoc/groups/public/documents/APCITY/UNPAN010012.pdf

15 'Keynote Address by Prime Minister Goh Chok Tong at the ASEAN Business and Investment Summit', 6 October 2003, Bali, Indonesia, available online at http://www.aseansec.org/15156.htm.
} 
Chinese economy, ASEAN members had the common perception of the need to push forward regional integration. However, they had to resolve issues of what kind of policies and standards are adopted and how domestic policies and regulatory frameworks are coordinated. Singapore and Thailand sought to accelerate market integration by providing a model for MRAs and standards harmonisation. At the same time, their active bilateral FTA strategies posed significant challenges for regional integration in Southeast Asia.

\section{The ASEAN divide problem}

Continuous process for regional integration was desirable for the entire ASEAN members. However, the accelerated process of market liberalisation for regional integration had a risk of provoking distributional problems by producing negative effects on the economy of less developed members through intensified competition. This issue was serious for ASEAN that had the development gap problem when it achieved the ASEAN 10 by accepting the Indochina countries (Cambodia, Laos, Myanmar and Vietnam, CLMV) in the late 1990s. ${ }^{16}$ There were serious gaps in development between the old members and the newly joined CLMV. Indeed, per capita GDP in the old ASEAN members declined after 1996, but gap between the old and new ASEAN members remained stark (Table 1 ). The CLMV contributed only $8 \%$ of total GDP in 2003, compared with their $28 \%$ contribution in terms of population. Singaporeans were on average 35 times richer than the Vietnamese and 68 times than the Cambodians. The resolution of development divide was a serious hurdle to deeper integration.

Table 1 Population and GDP in ASEAN, 2003

\begin{tabular}{|c|r|r|r|}
\hline & Population (million) & GDP (US\$ billion) & Per capita GDP (US\$) \\
\hline Brunei & 0.36 & 4.7 & 13,244 \\
\hline Cambodia & 13.40 & 4.2 & 314 \\
\hline
\end{tabular}

16 In 1995, Vietnam became a member of the association. Then, the ASEAN members invited the heads of Myanmar, Cambodia and Laos to the fifth ASEAN summit in December 1995. Subsequently, the admission of Myanmar and Laos was formally agreed at an ASEAN Foreign Ministers' meeting in May 1997, and they became an official member two months later. Cambodia's accession was deferred until 1999 due to its troublesome rapturous domestic affairs. 


\begin{tabular}{|c|r|r|r|}
\hline Indonesia & 214.67 & 208.6 & 972 \\
\hline Laos & 5.66 & 2.0 & 361 \\
\hline Malaysia & 24.77 & 103.7 & 4,187 \\
\hline Myanmar & 49.36 & 9.6 & 195 \\
\hline Philippines & 81.50 & 79.3 & 973 \\
\hline Singapore & 4.25 & 91.4 & 21,495 \\
\hline Thailand & 62.01 & 143.3 & 2,311 \\
\hline Vietnam & 81.31 & 39.0 & 480 \\
\hline ASEAN & 537.31 & 686.3 & 1,277 \\
\hline Share of CLMV & $27.9 \%$ & & \\
\hline
\end{tabular}

Source: ASEAN Secretariat.

The state that proposed a concrete policy to cope with the development gap problem was Singapore. At the fourth informal summit in November 2000, Singaporean Prime Minister Goh Chok Tong proposed the Initiative for ASEAN Integration (IAI). The IAI aimed to narrow development divide between ASEAN's old and new members, promote equitable economic development, and help alleviate poverty in the new members. In February 2001, ASEAN Secretariat and representatives of CLMV agreed to set up the Task Force on the IAI. At the thirty-fourth ASEAN Ministerial Meeting (AMM) in July 2001, Foreign Ministers recognised the need to address the development gap by issuing the Hanoi Declaration on Narrowing Development Gap for Close ASEAN Integration. The declaration contained basic guidelines for measures in four areas: infrastructure, human resource development, information and communication technology, and regional economic integration.

ASEAN leaders approved the IAI Work Plan for Narrowing the Development Gap within ASEAN at the eighth summit in November 2002. The initial number of projects in the Work Plan was 48, and the number increased to 100 by May 2005. ${ }^{17}$ Indeed, Singapore's contribution to the IAI Work Plan was not significant. Its amount was ranked the fourth among the ASEAN six (Table 2). However, Singapore has

\footnotetext{
17 Funding was secured for 80 projects, of which 44 projects were completed, 21 projects were under implementation, and 15 projects secured firm funding and were in the planning stage (ASEAN Secretariat 2005b, p. 2).
} 
contributed a large amount to projects other than the IAI Work Plan, providing the $33.3 \%$ of total contributions to CLMV by the ASEAN six.

Table 2 ASEAN-6 Contribution to CLMV (US\$)

\begin{tabular}{|c|r|r|r|r|}
\hline & $\begin{array}{r}\text { Contribution } \\
\text { to IAI work plan }\end{array}$ & \multicolumn{2}{|c|}{$\begin{array}{c}\text { Contribution other } \\
\text { than IAI work plan }\end{array}$} & \multicolumn{2}{|c|}{ contribution } \\
\hline Brunei & $1,500,000$ & 358,605 & $1,858,605$ & 1.1 \\
\hline Indonesia & 599,000 & 135,054 & 734,054 & 0.4 \\
\hline Malaysia & 892,407 & $4,362,151$ & $5,254,558$ & 3.2 \\
\hline Philippines & 2,832 & 261,833 & 264,665 & 0.2 \\
\hline Singapore & 474,263 & $53,920,732$ & $54,394,995$ & 33.3 \\
\hline Thailand & 419,881 & 100,358255 & $100,778,136$ & 61.7 \\
\hline Total & $3,888,383$ & $159,396,630$ & $163,285,013$ & 99.9 \\
\hline
\end{tabular}

Note: The figures are as of April 2005.

Source: ASEAN Secretariat (2005b, p. 10).

The promotion of the IAI was accompanied by the strengthened role and function of the ASEAN Secretariat. The Hanoi Declaration on Narrowing Development Gap endorsed the establishment of an IAI Unit within the ASEAN Secretariat. The unit has secured the matching of a specific project with donors including ASEAN members, dialogue partners, and international aid agencies, and followed up the progress of the projects. The unit's functions remain weak, but its establishment implied ASEAN members' willingness to facilitate the choice in and observance of a system to resolve the distributional problem in the region.

Apart from the IAI, Thailand, which has direct borders with Indochina countries, has advanced a distinctive programme designed to sustain their development. At a special summit on SARS (severe acute respiratory syndrome) in Bangkok in April 2003, Thai Prime Minister Thaksin Shinawatra informally raised the idea of developing the Economic Cooperation Strategy (ECS) with leaders of Cambodia, Laos and Myanmar. The leaders of the four states, then, held the first ECS summit in November 2003. They adopted the Bagan Declaration in which the ECS was renamed into the AyeyawadyChao Phraya-Mekong Economic Cooperation Strategy (ACMECS) after the name of 
main rivers running through the region. Vietnam was not an original member but joined the ACMECS group in May 2004.

The Bagan Declaration clarified the objectives of the ACMECS and identified five priority areas of cooperation: trade and investment facilitation, agricultural and industrial cooperation, transport linkages, tourism cooperation, and human resources development. As a concrete path to cooperation, the Economic Cooperation Strategy Plan of Action (ECSPA) was formulated. The ECSPA, a 10-year timeframe from 2003, spelled out cooperative plans to carry out 46 common projects and 224 bilateral projects. All projects were divided into three phases: the short term (2003-2005), the medium term (2006-2008), and the long term (2009-2012). Moreover, the members sought to promote cooperation through sister city programmes, and a pilot sister city agreement was concluded between Trat in Thailand and Kok Kong in Cambodia, Mukkadan in Thailand and Savannakhet in Laos, as well as Mae Sot in Thailand and Myawaddy in Myanmar.

The Thai government advanced the ACMECS projects with various motivations. First, it aimed to improve Thai's industrial competitiveness by utilising cheap labour and resources in neighbouring countries. Thai's ACMECS projects were tied-aid, demanding the use of Thai's firms and products at least 50 \% (Kondo 2004, p. 16). Second, the Thai government sought to resolve social problems caused by its neighbouring countries. The inflows of illegal immigrants and drugs from the neighbouring countries caused increases in crimes and HIV/AIDS. Thailand aimed to reduce illegal immigrants by supporting economic development in the Indochina countries (Watanabe and Fusasaki 2005, p. 39). Third, Thailand had to strengthen linkages with Indochina countries as a counterbalance towards China. China has strengthened its influence on Myanmar by increased economic aid and mutual visit of senior leaders (Yoshimatsu 2004, pp. 422-24). Moreover, after China and ASEAN signed the Framework Agreement on China-ASEAN Comprehensive Economic Cooperation in November 2002, China provided substantial concessions with Indochina countries. These measures included the grant of special preferential tariff treatments for some goods from Cambodia, Laos and Myanmar, and offer of US\$5 million to help 
navigation along the upper stretches of the Mekong River in Laos, Myanmar and Thailand. ${ }^{18}$

It might be possible to regard the IAI as a corresponding programme to the EC's policy to strengthen its 'structural funds' in preparation for the single market. ${ }^{19}$ The role that Singapore and Thailand sought to play resembles to that of Germany in the EC, and they surely have contributed a lion's shares to the CLMV. However, Singapore and Thailand might not hold sufficient capabilities to become a paymaster for the Indochina countries. Singapore retains the highest per capita income and technology level, but it was ranked the fourth among ASEAN members in terms of total GDP in 2003 (Table 1). Thailand was ranked the second, but its per capita income was below Malaysia. Thus, their economic and technical capabilities are not comparable to those of Germany in the EC, which represented the dominant economic position by one country, sharing almost one-quarter of the community’s GDP and external/internal trade (Mattli 1999, p. 102).

Thailand and Singapore played a coordination role in securing funds from its neighbouring countries. In November 2004, Thailand hosted the ACMECS Special SOM and Ministerial Retreat with special session meetings between ACMECS members and development partners (Australia, New Zealand, France, Germany, Japan and Asian Development Bank). Japan, Germany, and France showed interest in the ACMECS projects (Watanabe and Fusasaki 2005, p. 43). The IAI was presented as a flexible framework that allows ASEAN members, ASEAN dialogue partners and other interested parties to contribute to narrowing the development gap. The IAI projects have been advanced with financial support from ASEAN's dialogue partners such as South Korea, Japan, and India. South Korea has contributed US\$5 million to fund five IAI projects in infrastructure, trade, and information and communications technology. Japan has contributed to the IAI through the ASEAN-Japan Solidarity Fund, Japan-ASEAN General Exchange Fund (JAGEF), and JICA. The top five donors contributed to

\footnotetext{
18 'Press Statement by the Chairman of the seventh ASEAN Summit and the Three ASEAN + 1 Summits’, available online at http://www.aseansec.org/menu_asean+3.htm.

19 In February 1989, the European Council agreed that by 1992, the amount of EC structural funds should be doubled to compensate depressed regions for intensified competition resulting from a unified market (Hufbauer 1990, p. 11).
} 
US\$13.7 million out of total US\$20.1 million worth of projects in grants (ASEAN Secretariat 2005a, p. 7).

Thus, coordination games emerged as a serious challenge to ASEAN's integration after the association completed the ASEAN ten. Although the ASEAN Secretariat strengthened internal organisation in order to cope with distributional problems, its influence was still weak. Instead, Singapore and Thailand began to play a pivotal role. Singapore launched a programme to rectify development gaps between the old and new members. Thailand also proceeded with an independent strategy to sustain economic development in the Indochina countries. While both states have provided the preponderant share of financial support for the Indochina countries, the overall economic capabilities were limited. Accordingly, they sought to gain economic support from extra-regional countries.

\section{CONCLUSIONS}

This article has examined how ASEAN members have advanced regional integration by overcoming dilemmas from collaboration games and coordination games. Unlike the EU, ASEAN members have little interest in developing the organisation into a supranational agency, nor being led by a hegemonic regional power that has the willingness and capabilities to enforce the rules of interaction on other states. Under such conditions, how have the ASEAN members tried to achieve a steady path to regional cohesion?

Given growing moves toward regionalism in North America and Europe, ASEAN members decided on the formation of AFTA in 1992. Afterwards, they accelerated the schedule of trade liberalisation for AFTA and expanded the scope of market integration, targeting investment areas and services. However, its implementation process was accompanied by some members' defection from implementing agreements that were non-binding. The problem of collaboration games clearly appeared in AFTA's implementation process.

In the new millennium, ASEAN members launched a new programme for market integration: the formation of the AEC by 2020. In order to achieve this goal, they needed to overcome dilemmas from collaboration games that were seen in the previous cohesion programme. They developed mechanisms to ensure the proper implementation 
of agreements and provided stronger dispute settlement mechanisms. These mechanisms aimed at mitigating a state's incentives to defect from the agreements and reducing ambiguity about the agreements. Moreover, the ASEAN members strengthened the centralised nature of the ASEAN Secretariat by granting more functions and roles. Indeed, Southeast Asia remains beholden to sovereignty as the fundamental principle of stability, and the ASEAN members have no intention of relinquishing sovereignty to a supranational agent. However, this does not mean that they have done nothing to strengthen the codes of conduct for the compliance of agreements. They gradually provided the existing organisation with more formal, stronger authority.

As far as coordination problems are concerned, the development of formal institutions was not noteworthy. Indeed, an internal organ to coordinate distribution problems was set up, but ASEAN's overall functions were still limited. However, two states began to play a leadership role in settling dilemma from coordination problems. Singapore and Thailand jointly sought to become a focal point for standards harmonisation and MRAs in order to achieve desirable regional integration. They also took the lead in resolving distributional problems from closer market integration among the members by launching new policies to provide support for less developed Indochina countries.

A distinctive factor that has influenced the resolution of coordination problems in Southeast Asia was influences from the external environments and extra-regional states. On the positive side, some extra-regional states have contributed to the resolution of the problems. On the issues of standards harmonisation and development gap, ASEAN members received significant assistance from the extra-regional states. ASEAN, which lacks a paymaster state, located the resolution of distributional problems in the network of support from its dialogue partners. On the negative side, extra-regional power undermined the policy cohesion of ASEAN. Indeed, Thailand and Singapore began to play a significant role in leading the integration process. However, these two states created and strengthened moves that might weaken internal integration by maintaining close economic linkages with extra-regional states. ASEAN, an organisation comprised of small states, has faced difficulty in resolving internal dilemma for close cooperation. A the same time, the members have to show capabilities to take advantage of external 
environments and the power to yield positive, not negative, effects on regional cohesion. 


\section{REFERENCES}

ASEAN Secretariat. ASEAN: Narrowing the Development Gap. Jakarta: ASEAN Secretariat, 2005a.

ASEAN Secretariat. "Initiative for ASEAN Integration (IAI) Work Plan for the CLMV Countries: Progress Report as at 15 May 2005”, 2005 b. http://www.aseansec.org/pdf/IAI-Article.pdf, accessed 10 November 2005.

Axelrod, Robert. The Evolution of Cooperation, New York: Basic Books, 1984.

Cowles, Maria Green. "Setting the Agenda for a New Europe: The ERT and EC 1992”, Journal of Common Market Studies 33, no.4 (1995): 501-526.

Dent, Christopher M. "The New Economic Bilateralism in Southeast Asia: RegionConvergent or Region-Divergent?”, International Relations of the Asia Pacific 6, no.1 (2005): 1-31.

Hew, Denis and Soesastro, Hadi. "Realizing the ASEAN Economic Community by 2020: ISEAS and ASEAN-ISIS Approaches”, ASEAN Economic Bulletin 20, no.3 (2003): 292-96.

Hufbauer, Gary Clyde. “Overview”, In Europe 1992: An American Perspective, edited by Gary Clyde Hufbauer. Washington, D.C.: Brookings Institution, 1990.

Hund, Markus. “From 'Neighbourhood Watch Group’ to Community?”, Australian Journal of International Affairs 56, no.1 (2002): 99-122.

Katzenstein, Peter J. "United Germany in integrating Europe”, In Tamed power: Germany in Europe, edited by Peter J. Katzenstein. Ithaca, N.Y.; London: Cornell University Press, 1997.

Kindleberger, Charles P. "Dominance and Leadership in the International Economy: Exploitation, Public Goods, and Free Rides,” International Studies Quarterly 25 (1981): 242-54.

Kondo, Masaki. "Mekon gawa chiiki ni okeru syuyo dona no enjo doko to sono imi" [Aid trends and implications of major donors in the Mekong River region], In ASEAN sinki kameikoku no keizai jizoku kanosei to keizai shien [economic 
sustainability of the new ASEAN members and economic assistance] edited by Kaigai Toshi Yushi Joho Zaidan. Tokyo: Kaigai Toshi Yushi Joho Zaidan, 2004.

Krasner, Stephen. “Global Communications and National Power”, World Politics 43, no.3 (1991): 336-366.

Martin Lisa and Simmons, Beth. "Theories and Empirical Studies of International Institutions”, International Organization 52, no.4 (1998): 729-757.

Martin, Lisa. "Interests, Power, and Multilateralism”, International Organization 46, no.4 (1992): 765-92.

Mattli, Walter. The Logic of Regional Integration: Europe and Beyond, Cambridge: Cambridge University Press, 1999.

Sandholtz, Wayne and Zysman, John. “1992: Recasting the European Bargain”, World Politics 42, no.1 (1989): 95-128.

Schelling, Thomas C. The Strategy of Conflict, Cambridge, MA: Harvard University Press, 1960.

Schwarz, Adam and Villinger, Roland. “Integrating Southeast Asia’s economies”, McKinsey Quarterly, 2004-1:36-47

Severino, Rodolfo C. "Regional Integration in Europe and in Asia", Asia Europe Journal 1 (2003): 475-79.

Snidal, Duncan. “Coordination versus Prisoners' Dilemma: Implications for International Cooperation and Regimes”, American Political Science Review 79, no.4 (1985): 923-42.

Stein, Arthur A. "Coordination and Collaboration: Regimes in an Anarchic World”, In International Regimes, edited by Steven D. Krasner. Ithaca, N.Y.: Cornell University Press, 1983.

Tan, Suen Fong. “European Integration: A Model for South-East Asia?”, Asia Europe Journal 3 (2005): 7-11.

Watanabe, Keiko and Susakaki, Rie. Kanbojia unyu sekuta ni okeru enjo kyocho [Aid coordination in the transport sector in Cambodia], Tokyo: Kokusai Kaihatsu Kenkyu Senta, 2005. 
Yamakage, Susumu. ASEAN pawaa: Ajia taiheiyo no chukaku he [ASEAN Power: Toward a Centre of the Asia-Pacific], Tokyo: Tokyo Daigaku Shuppankai, 1997. Yoshimatsu Hidetaka. “Regional Linkages and Japan’s Foreign Aid Policy towards Myanmar”, Asian Profile 32, no.5 (2004): 411-27. 


\section{$\underline{\text { CSGR Working Paper Series }}$}

175/05 October

176/05 October

177/05 October

178/05 November Citizenship

179/05 November

180/05 November

181/05 November

182/05 November

183/05 December

184/05 December

185/05 December

186/05 December

187/06 January

188/06, January

189/06, January

190/06, January
Dunja Speiser and Paul-Simon Handy

The State, its Failure and External Intervention in Africa

Dwijen Rangnekar

'No pills for poor people? Understanding the Disembowelment of India's Patent Regime.'

Alexander Macleod

'Globalisation, Regionalisation and the Americas - The Free Trade Area of the Americas: Fuelling the 'race to the bottom'?'

Daniel Drache and Marc D. Froese

The Global Cultural Commons after Cancun: Identity, Diversity and

Fuad Aleskerov

Power indices taking into account agents’ preferences

Ariel Buira

The Bretton Woods Institutions: Governance without Legitimacy?

Jan-Erik Lane

International Organisation Analysed with the Power Index Method.

Claudia M. Fabbri

The Constructivist Promise and Regional Integration: An Answer to 'Old' and 'New' Puzzles: The South American Case.

Heribert Dieter

Bilateral Trade Afreements in the Asia-Pacific: Wise or Foolish Policies?

Gero Erdmann

Hesitant Bedfellows: The German Stiftungen and Party Aid in Africa. Attempt at an Assessment

Nicola Maaser and Stefan Napel

Equal Representation in Two-tier Voting Systems

Gianluca Grimalda

Can Labour Market Rigidity Lead to Economic Efficiency? The Technological Change Link

Leonardo Ramos

Collective political agency in the XXIst century: Civil society in an age of globalization

Mustafizur Rahman and Wasel Bin Shadat NAMA Negotiations in the WTO and Preference Erosion: Concerns of Bangladesh and Other Regional LDCs

Amrita Dhillon, Javier Garcia-Fronti, Sayantan Ghosal and Marcus Miller Bargaining and Sustainability: The Argentine Debt Swap

Marcus Miller, Javier Garcia-Fronti and Lei Zhang 
Contradictionary devaluation and credit crunch: Analysing Argentina.

\begin{tabular}{|c|c|}
\hline 191/06, January & $\begin{array}{l}\text { Wyn Grant } \\
\text { Why It Won't Be Like This All The Time: the Shift from Duopoly to } \\
\text { Oligopoly in Agricultural Trade }\end{array}$ \\
\hline 192.06, January & $\begin{array}{l}\text { Michael Keating } \\
\text { Global best practice(s) and electricity sector reform in Uganda }\end{array}$ \\
\hline 193/06 February & $\begin{array}{l}\text { Natalie Chen, Paola Conconi and Carlo Perroni } \\
\text { Does migration empower married women? }\end{array}$ \\
\hline 194/06 February & $\begin{array}{l}\text { Emanuel Kohlscheen } \\
\text { Why are there serial defaulters? Quasi-experimental evidence from } \\
\text { constitutions. }\end{array}$ \\
\hline 195/06 March & $\begin{array}{l}\text { Torsten Strulik } \\
\text { Knowledge politics in the field of global finance? The emergence of a } \\
\text { cognitive approach in banking supervision }\end{array}$ \\
\hline 196/06 March & $\begin{array}{l}\text { Mark Beeson and Hidetaka Yoshimatsu } \\
\text { Asia’s Odd Men Out: Australia, Japan, and the Politics of Regionalism }\end{array}$ \\
\hline 197/06 March & $\begin{array}{l}\text { Javier Garcia Fronti and Lei Zhang } \\
\text { Political Instability and the Peso Problem }\end{array}$ \\
\hline 198/06 March & $\begin{array}{l}\text { Hidetaka YOSHIMATSU } \\
\text { Collective Action Problems and Regional Integration in ASEAN }\end{array}$ \\
\hline
\end{tabular}

Centre for the Study of Globalisation and Regionalisation

University of Warwick

Coventry CV4 7AL, UK

Tel: +44 (0)24 76572533

Fax: +44 (0)24 76572548

Email: csgr@warwick.ac.uk

Web address: http://www.csgr.org 